Conference report

\title{
Human monkeypox - After 40 years, an unintended consequence of smallpox eradication
}

\author{
Karl Simpson ${ }^{\mathrm{a}, *}$, David Heymann ${ }^{\mathrm{b}}$, Colin S. Brown ${ }^{\mathrm{c}}$, W. John Edmunds ${ }^{\mathrm{b}}$, Jesper Elsgaard ${ }^{\mathrm{d}}$, Paul Fine ${ }^{\mathrm{b}}$, \\ Hubertus Hochrein ${ }^{e}$, Nicole A. Hoff ${ }^{f}$, Andrew Green ${ }^{g}$, Chikwe Ihekweazu ${ }^{h}$, Terry C. Jones ${ }^{i, j}$, Swaib Lule ${ }^{k}$, \\ Jane Maclennan $^{\mathrm{e}}$, Andrea McCollum ${ }^{\mathrm{l}}$, Barbara Mühlemann ${ }^{\mathrm{i}, \mathrm{j}}$, Emily Nightingale ${ }^{\mathrm{m}}$, Dimie Ogoina ${ }^{\mathrm{n}}$, \\ Adesola Ogunleye $^{\mathrm{h}}$, Brett Petersen ${ }^{\mathrm{l}}$, Jacqueline Powell ${ }^{\mathrm{o}}$, Ollie Quantick ${ }^{\mathrm{p}}$, Anne W. Rimoin ${ }^{\mathrm{f}}$, \\ David Ulaeato ${ }^{\mathrm{q}}$, Andy Wapling ${ }^{\mathrm{r}}$
}

a JKS Bioscience Limited, 2 Midanbury Court, 44 Midanbury Lane, Southampton SO18 4HF, UK

${ }^{\mathrm{b}}$ London School of Hygiene E Tropical Medicine, Keppel St, Bloomsbury, London WC1E 7HT, UK

${ }^{c}$ Public Health England, Colindale, 61 Colindale Avenue, London NW9 5EQ UK

d Bavarian Nordic A/S, Hejreskovvej 10A, DK-3490 Kvistgård, Denmark

e Bavarian Nordic GmbH, Fraunhoferstraße 13, 82152 Planegg, Germany

${ }^{\mathrm{f}}$ Fielding School of Public Health, UCLA, 50 Charles E Young Dr S, Los Angeles, CA 90095, United States

${ }^{\mathrm{g}}$ Royal Centre of Defence Medicine, Level 2 QEHB, Mindelsohn Way, Edgbaston, Birmingham B15 2WB,UK

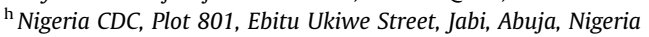

${ }^{\mathrm{i}}$ Centre for Pathogen Evolution, Department of Zoology, University of Cambridge, Downing St., Cambridge CB2 3EJ, UK

${ }^{\mathrm{j}}$ Institute of Virology, Charité, Universitätsmedizin Charitéplatz 1, 10117 Berlin, Germany

${ }^{\mathrm{k}}$ University College London, Faculty of Population Health Sciences, 30 Guilford Street, London WC1N 1EH, UK

${ }^{1}$ Centers for Disease Control and Prevention, 1600 Clifton Rd. NE, CDC, Atlanta, GA 30333, USA

${ }^{\mathrm{m}}$ The Forge Veterinary Centre, 93b Head Street, Halstead, Essex CO9 2AZ, UK

${ }^{n}$ Niger Delta University/Niger Delta University Teaching Hospital, Bayelsa, Nigeria

${ }^{\circ}$ Bavarian Nordic Inc, 3025 Carrington Mill Blvd, Morrisville, NC 27560, USA

${ }^{\mathrm{p}}$ SO1 Public Health and Health Protection, Army Headquarters, Ground Floor, Zone1, Blenheim Bd, Marlborough Lines, Monxton Road, Andover, Hampshire SP11 8HJ, UK

${ }^{\natural}$ CBR Division, Defence Science \& Technology Laboratory, Porton Down, Salisbury SP4 0JQ UK

${ }^{\mathrm{r}}$ Regional Head of Emergency Preparedness, Resilience and Response, NHS England (South West E South East), UK

\section{A R T I C L E I N F O}

Article history:

Received 26 February 2020

Accepted 26 April 2020

Available online 13 May 2020

\section{Keywords:}

Smallpox

Monkeypox

Orthopox

Eradication

Risk

Epidemiology

Vaccines

\section{A B S T R A C T}

Smallpox eradication, coordinated by the WHO and certified 40 years ago, led to the cessation of routine smallpox vaccination in most countries. It is estimated that over $70 \%$ of the world's population is no longer protected against smallpox, and through cross-immunity, to closely related orthopox viruses such as monkeypox. Monkeypox is now a re-emerging disease.

Monkeypox is endemic in as yet unconfirmed animal reservoirs in sub-Saharan Africa, while its human epidemiology appears to be changing. Monkeypox in small animals imported from Ghana as exotic pets was at the origin of an outbreak of human monkeypox in the USA in 2003. Travellers infected in Nigeria were at the origin of monkeypox cases in the UK in 2018 and 2019, Israel in 2018 and Singapore in2019. Together with sporadic reports of human infections with other orthopox viruses, these facts invite speculation that emergent or re-emergent human monkeypox might fill the epidemiological niche vacated by smallpox.

An ad-hoc and unofficial group of interested experts met to consider these issues at Chatham House, London in June 2019, in order to review available data and identify monkeypox-related research gaps.

Abbreviations: CDC, Centers for Disease Control, Atlanta USA; DRC, Democratic Republic of Congo (formerly Zaire); EMA, European Medicines Agency; FDA, United States

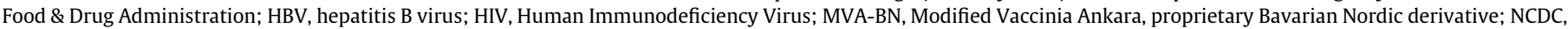
Nigeria Centre for Disease Control; PCR, polymerase chain reaction; WHO, World Health Organization.

* Corresponding author.

E-mail addresses: karl.simpson@jksbioscience.co.uk (K. Simpson), David.Heymann@LSHTM.ac.uk (D. Heymann), Colin.Brown@phe.gov.uk (C.S. Brown), John.

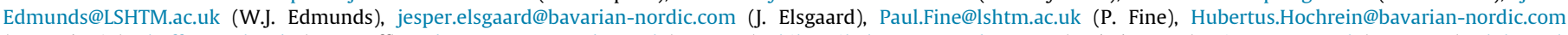

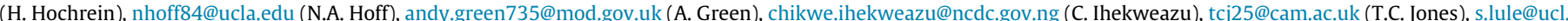

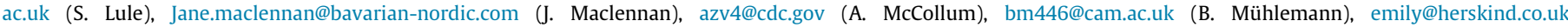

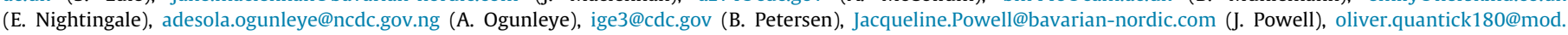
gov.uk (O. Quantick), arimoin@ucla.edu (A.W. Rimoin), dulaeto@dstl.gov.uk (D. Ulaeato), andy.wapling@nhs.net (A. Wapling). 
Gaps identified by the experts included:

- understanding of zoonotic hosts, reservoirs and vectors.

- risks associated with transmission.

- full description of the clinical spectrum and the natural history of infection including an estimation of the prevalence of monkeypox specific antibodies in humans living in areas of emergence.

The experts further agreed on the need for a better understanding of the genomic evolution and changing epidemiology of orthopox viruses, the usefulness of in-field genomic diagnostics, and the best disease control strategies, including the possibility of vaccination with new generation non-replicating smallpox vaccines and treatment with recently developed antivirals.

\section{Introduction}

The vaccinia virus vaccine that eradicated smallpox also protected against other orthopox infections, and if given within four days of infection could modify or prevent onset of clinical disease [1]. With the eradication of smallpox and the subsequent cessation of routine smallpox vaccination [2,3], human monkeypox appeared with increasing frequency in unvaccinated populations. Secondgeneration smallpox vaccines have been demonstrated to protect against monkeypox [4,5]. However, better understanding of the epidemiology of monkeypox virus has gained importance.

Variola virus, the causative agent of smallpox, is thought to have adapted to the human host as early as 3 to 4 thousand years ago. Smallpox immunisation had existed in some form for at least one thousand years, according to Chinese records [6,7]. Rational vaccine design began with Jenner's 1796 cowpox vaccine [8], made from a virus that caused a usually mild disease, transmitted to humans by animal hosts. Vaccination laid the basis for the eradication of Variola in 1980 [9]. Several orthopox viruses, including the monkeypox virus, are thought to have caused similar mild and sporadic human illness prior to the innovation of smallpox vaccination [10], and remain in circulation in animal hosts with periodic emergence in human populations. Variola minor (sometimes called alastrim) was a less common and genetically distinct form of the variola virus [11]. In contrast to the $30-50 \%$ fatality rate of smallpox, the Variola minor fatality rate was reportedly less than $1 \%$. Many Variola minor patients felt quite well, were mobile and were able to infect their contacts, providing protection to Variola major [12]. Vaccination and protective Variola minor exposure contributed to smallpox eradication and likely reduced the number of other human orthopox infections.

Just as smallpox virus appears to have evolved into two distinct clades, so Monkeypox displays two distinct clades, Congo Basin and West African [13]. With monkeypox, the Congo Basin clade has reported mortality at about 10\% [14], whereas the West African clade usually displays fatal outcomes in less than $1 \%$ of cases, although, this was observed to be much higher in HIV patients [15].

As originally noted by Jenner, infection with one orthopox virus, cowpox (and subsequently, vaccinia-derived vaccines), offered smallpox protection. However, the proportion of smallpox vaccinated individuals has fallen from over $80 \%$ in 1980 , to less than $30 \%$ today [16]. In some developing nations, young nonvaccinated individuals exceed $75 \%$ of the population [17]. Such individuals are almost certainly susceptible to monkeypox virus infection.

Monkeypox was first identified in Denmark in 1958, following an outbreak of pustular disease in a macaque colony [18]. The macaques had been imported from Singapore. The first human monkeypox case was identified in the Democratic Republic of Congo (DRC, then Zaire) in 1970 as the incidence of smallpox was decreasing $[19,20]$. The true burden of monkeypox disease is unknown, and many countries, which may harbour the disease, have not included monkeypox screening into routine surveillance systems. The prevalence of asymptomatic infection is not understood, should it occur in human populations.

Despite-re-emergent human monkeypox disease, the animal reservoirs of monkeypox viruses and the human behaviours that facilitate initial animal to human transmission are unconfirmed. It has been shown that in intermediate hosts the virus can be transmitted from one animal to another, and subsequently to humans. This occurred in the US Midwest outbreak, when 47 confirmed and probable cases, including many children, were infected by prairie dogs thought to have contracted monkeypox from rodents shipped to the United States from Ghana [21].

In June 2019 an informal seminar brought together a group of experts to review the status of human monkeypox disease, highlighting facts and deficient understanding. Included in the group were: epidemiologists based in the UK and the US; field epidemiologists based in Nigeria and DRC where current outbreaks are occurring; experts in DNA virus genomics and evolution; and observers from a pharmaceutical company that has developed and is marketing a non-replicating vaccine for both smallpox and monkeypox indications.

\section{Re-emergent monkeypox in Africa}

Hypothesised factors in the emergence or re-emergence of monkeypox disease include [22,23]:

- Climate change

- Rain Forest exploitation

- Geopolitical and armed conflicts in disease areas

- Highly mobile populations

- Waning herd immunity, following cessation of smallpox vaccination.

After the eradication of smallpox, there was concern that the monkeypox virus might fill the epidemiological niche left by smallpox [24]. Smallpox had no known zoonotic host and was transmitted only on a human-to-human basis, whereas monkeypox may be transmitted to man by animal hosts. WHO-sponsored serological surveys were conducted in rural communities in West and Central Africa where human monkeypox was sporadically occurring. Prior to 1986 , population-based surveys suggested that orthopox virus antibodies were present in $12-15 \%$ of children. The mean age of patients was just 4.4 years. Cases of monkeypox were linked to animal sources in 245 of 338 cases [25]. A major outbreak of human monkeypox occurred in Katako-Combe, Zaire in 1996, From February 1996 to February 1997, 89 persons in this outbreak were diagnosed with human monkeypox $[19,26]$. $73 \%$ of cases reported contact with another human case while $27 \%$ had known contact 
with a wild animal. Prior to 1996, chains of transmission were short and infrequent, variously reported as involving up to 3-5 non-vaccinated persons. Several longer chains of transmission occurred during the 1996-1997 Katako-Combe outbreak, with up to 7 non-vaccinated persons infected from the same index case. From 1998, numbers of infections increased, with an increase in mean age [25]. A 2007 study showed orthopox antibodies in unvaccinated residents of the Likouala region (Republic of Congo, ROC, not DRC) [27]. By 2006-7 a very significant 20-fold increase in human monkeypox was reported in DRC [28]. Only $24.5 \%$ of the population appeared to have been vaccinated. Was this emerging infection out of control [29]?

In 2017, outbreaks of human monkeypox in Nigeria were preceded by very heavy rainfall and flooding that is hypothesised to have brought animal hosts and human populations into close proximity, as both sought higher ground and dry environments [30]. The outbreak was first reported to the Nigerian Centre for Disease Control (NCDC) in September 2017, following an unknown rash illness in southern Nigeria, and regular reports followed [31]. Active surveillance confirmed human monkeypox, and as of September 2019, a total of 176 human monkeypox cases had been confirmed from 18 states [32,33].

Previously, there had been one reported outbreak of human monkeypox in Nigeria in the 1970s, and after that, three sporadic cases were reported before the onset of the 2017 epidemic [34]. The chains of transmission investigated in the current outbreak suggest a primary infection contracted from an animal, with subsequent human-to-human transmission. Human-to-human transmission has been demonstrated among family contacts, and in prison populations, but human-to-human chain lengths appear to be short at 1-3 individuals in each link, although this requires more analysis [32,35]. Monkeypox laboratory diagnosis by PCR has been established by NCDC [36] and suggests that young male adults are most affected. A case fatality rate of $5.6 \%$ has been recorded, with most deaths among HIV infected patients [37]. The case fatality rate, excluding those with HIV infection is reported as $<2 \%$. Persons vaccinated prior to 1980 had a five-fold lower risk of monkeypox compared to those who had not been vaccinated [24]. Human-to-human transmission of monkeypox is now regularly observed and the disease has become more common.

Risk factors for infection are unclear, with confirmed animal contact in approximately $10 \%$ of cases, while the prevalence of asymptomatic infection, should it occur, remains unknown. Sexual transmission has been hypothesised for some cases with genital and groin lesions [37]. The current research focus in Nigeria is on epidemiological risk factors, animal reservoirs and HIV co-infection. Control and prevention measures include education and personal hygiene, drawing on known epidemiology and risk factors. Vaccination has been considered for healthcare workers in treatment centres but was not initiated. Human monkeypox is being added to routine disease surveillance protocols, with genomic studies and serological surveys being planned. Additional questions that could be examined include, transmission routes from human-to-human, and the natural history of dual monkeypox/HIV infection.

Social issues have emerged, including the stigma of being diagnosed with monkeypox. One suicide was reported [37]. Many patients with monkeypox feel relatively well and containment is complicated by a desire to return to a normal life - often expressed quite strongly. The same sentiment was expressed by a person secondarily infected in the 2018 UK cases [38].

\section{International spread of human monkeypox}

In 2003 an outbreak of human monkeypox occurred in the USA [21]. It was initiated by rodents imported from Ghana to be sold as exotic pets. It is thought that these rodents infected co-housed prairie dogs, also sold as pets, through some type of animal to animal contact. 47 confirmed and probable cases were reported, but there were no deaths. The outbreak consisted mainly of isolated skin lesions. Smallpox vaccine (DryVax, Wyeth) was offered to those who had direct physical contact with human cases and rodents that were sold. Two cases in the 2003 outbreak in the USA may have involved human-to-human transmission, but contact with infected rodents could not be excluded.

In September 2018, there were two unrelated importations of monkeypox to the UK, by two persons travelling from Nigeria [39]. One was a Nigerian naval officer who came to the UK for a training course. The other a Nigerian businessman. Both were well before travelling, and developed skin lesions after arrival in the UK. Soiled bedsheets probably led to infection of a hospital cleaner [40], the first confirmed case of human-to-human transmission outside Africa. In 2018, all UK patients were rapidly diagnosed and isolated with over 200 contacts identified and offered smallpox vaccination (Imvanex, Bavarian Nordic) [41,42]. In December 2019 a further case of human monkeypox was confirmed in the UK, again imported from Nigeria [43]. Contact tracing was initiated and smallpox vaccine (Imvanex) was procured.

In 2018 human monkeypox was imported to Israel by an Israeli resident who lived and worked in Nigeria [44]. He became ill after his return to Israel, and PCR and Electron Microscopy confirmed infection with the monkeypox virus. Following diagnosis, the patient was isolated, and 16 contacts were identified and offered smallpox vaccination (ACAM2000, Emergent Biosolutions). No secondary transmission is known to have occurred [45].

In 2019, a Nigerian travelling to Singapore for a training course developed skin lesions shortly after arrival and was diagnosed with human monkeypox. 23 close contacts were identified, were offered smallpox vaccination (ACAM2000) and were placed under quarantine at home or in a government facility for 21 days monitoring [46,47].

The smallpox vaccines offered in all these instances were used off license.

\section{New genomic tools aid diagnosis, epidemiology and evolutionary studies}

The monkeypox viruses isolated recently from patients in Nigeria, the UK, Israel and Singapore were quickly diagnosed and identified as West African monkeypox virus using PCR and genetic sequencing. Recent studies of the monkeypox virus in the DRC and Nigeria examined isolates from humans [48,49], and potential animal hosts [50]. Complementing PCR, newer technologies such as (Minion nucleotide sequencing (Oxford Nanopore) [51], might allow field sequencing of the monkeypox virus in animals commonly killed as bushmeat. This technology can be used with little infrastructure and ensures rapid data generation, as was demonstrated in the West African Ebola outbreak of 2013-2016 [52]. Detailed animal data will require the establishment of protocols for sample collection and preparation. To date, only anecdotal data link bushmeat hunting and preparation with monkeypox infection.

Two major monkeypox clades-West African and Congo Basinhave been identified [13], and all reported human monkeypox outside Africa has been caused by the West African clade [50]. West African monkeypox is associated with lower mortality, less severe illness, and less human-to-human transmission than Congo Basin monkeypox. However, these observations were based on a small number of infections $(<100)$ observed since the 1970s. The larger number of infections identified from Nigeria has shown that mortality, severe illness, and human-to-human transmission can occur [37]. More work is needed in order to fully describe the epidemiology and impact of West African monkeypox. 
The evolutionary history of monkeypox virus is unclear. Orthopox viruses differ in gene content, in particular genes affecting virulence and host range. Viruses with narrow host ranges contain fewer genes, for example; variola virus has about 165 genes, whereas those with broad host ranges have more. Cowpox viruses contain about 214 genes. The smallpox virus encodes virulence factors that modulate the human immune system [53,54], and similar virulence factors exist in monkeypox virus [55]. Understanding of the genetic basis for these differences is incomplete. The availability of additional full monkeypox virus genomes (currently there are 59 complete genomes in the NCBI nucleotide database [56], may allow researchers to observe future adaptations associated with changes in virus properties.

The study of orthopox DNA isolated from historical samples may provide information on the evolution, pathogenicity and stability of the monkeypox virus. The isolation of DNA from Hepatitis $B$ virus (HBV) and identification of HBV genotypes from human remains up to 5000 years old illustrates this potential [57]. DNA can be isolated from ancient biological material such as found in burial sites and mummified remains [58]. DNA from monkeypox virus has been isolated from skin samples of five species of African rope squirrel (Funisciurus sp) up to 120 years old [59]. Appropriate historical specimens could provide clues about reservoirs and intermediate hosts, as well as past changes of the virus.

\section{The future}

Human monkeypox epidemiology has changed. With the cessation of widespread smallpox vaccination, increased study of the monkeypox virus, the human disease it causes, and its epidemiology are important. Monkeypox has been viewed as "just another neglected disease". Global travel and easy access to remote and potentially monkeypox-endemic regions are a cause for increasing global vigilance.

Investigation of human monkeypox outbreaks using modern tools is increasing understanding of the epidemiology of human monkeypox, including measures to prevent and respond to outbreaks. It must be continued, and as further information becomes available it should be used to parameterise epidemiological models in order to suggest the comparative effectiveness of interventions such as isolation, safe burial, contact tracing, antivirals and vaccines.

Funding for monkeypox research must be increased, and newly emerged orthopox viruses that cause disease in humans such as Akhmeta virus, identified in the Georgia Caucusus [60] or Alaskapox virus discovered in 2015 [61], add urgency to this need.

A recent systematic review of monkeypox epidemiology highlights both progress and deficits in our understanding [62]. Emphasis is placed on high-risk patient groups, nosocomial transmission and genetic strains. As monkeypox is no longer a rare disease, there is need for more rigorous epidemiological studies, with particular reference to zoonotic hosts [63], transmission potential [64-66] and human case severity. Enhanced fieldwork should address these issues with particular reference to:

- Identification of wild species which harbour these viruses in different areas of Africa

- Better definition of the clinical spectrum and severity of disease, including asymptomatic carriage and risk factors for acquisition

- Improved description of outbreak patterns by size and duration

- Measurement of risk of transmission associated with different sorts of contact with clinical cases

\section{Authors contributions}

Simpson organised the seminar that led to this publication. He wrote the article, reviewed and edited authors' contributions
Heymann Chaired the seminar and co-wrote the article, reviewed and edited authors' contributions

All co-authors contributed equally to the seminar with presentations and discussion. All made valued contributions to the final manuscript.

All authors have reviewed this work and have given their permission to be named as authors in this publication.

\section{Declaration of Competing Interest}

The authors declare the following financial interests/personal relationships which may be considered as potential competing interests: Authors Elsgaard, Hochrein, Maclennan and Powell are employees of Bavarian Nordic, manufacturer of a vaccine registered as Jynneos for smallpox and monkeypox indications in the USA (Imvanex for smallpox only in Europe and Imvamune for smallpox only in Canada. Simpson works as a consultant for Bavarian Nordic.

\section{Acknowledgements}

Chatham House, London provided a seminar venue and logistic support. Bavarian Nordic provided support for international travel.

\section{References}

[1] Hussain AN, Hussain F, Alam M and Cleri DJ. Smallpox Treatment \& Management. Medscape -November 11; 2019.

[2] MMWR Weekly 1997;46(14):304-307. https://www.cdc.gov/mmwr/preview/ mmwrhtml/00048673.htm.

[3] WHO Fact Sheet. https://www.who.int/news-room/fact-sheets/ detail/monkeypox [December 9, 2019].

[4] Bavarian Nordic website. http://www.bavarian-nordic.com/investor/news/ news.aspx? news=5758 [September 24, 2019].

[5] CDC Monkeypox and Smallpox Vaccine Guidance. https://www.cdc.gov/ poxvirus/monkeypox/clinicians/smallpox-vaccine.html [December 2, 2019].

[6] Hughes AL, Irausquin S, Friedman R. The Evolutionary Biology of Poxviruses Infect Genet Evol 2010;10(1):50.

[7] Needham J. Science and Civilisation in China: Volume 6, Part 6, Biology and Biological Technology. Cambridge University Press; 2000.

[8] Riedel S. Edward Jenner and the history of smallpox and vaccination. Proc (Bayl Univ Med Cent) 2005;18(1):21-5.

[9] WHO, Smallpox, Historic milestone underscores urgent need to invest in global health security and universal health coverage. https://www.who.int/csr/ disease/smallpox/en/ [December 13, 2019].

[10] Fenner F, Wiyyek R, Dumbell KR. The Orthopoxviruses. San Diego: Academic Press; 1989 [ISBN: 0-12-253045-4].

[11] Shchelkunov SN, Totmenin AV, Loparev VN, Safronov PF, Gutorov VV Chizhikov VE, et al. Alastrim Smallpox Variola Minor Virus Genome DNA Sequences. Virology 2000;266:361-86.

[12] Petersen BW, Damon I K in Mandell, Douglas and Bennett's Principles and Practice of Infectious Diseases, 8th ed. Elsevier Inc; 2015.

[13] Likos AM, Sammons SA, Olson VA, Frace AM, Li Y, et al. A tale of two clades: monkeypox viruses. J Gen Virol 2005;86:2661-72.

[14] Doshi RH, Guagliardo SAJ, Doty JB, Babeaux AD, et al. Epidemiologic and Ecologic Investigations of Monkeypox, Likouala Department, Republic of the Congo, 2017. Emerg Infect Dis 2019;25(2):273-81.

[15] Ogoina D, Izibewule JH, Ogunleye A, Ederiane E, Anebonam U, et al. The 2017 human monkeypox outbreak in Nigeria-Report of outbreak experience and response in the Niger Delta University Teaching Hospital, Bayelsa State, Nigeria. PLOS ONE 2019;14(4):e0214229.

[16] WHO, Smallpox vaccines. https://www.who.int/csr/disease/smallpox/ vaccines/en/ [December 4, 2019].

[17] World Population Review. http://worldpopulationreview.com/countries/ median-age/ [January 22, 2020].

[18] von Magnus P, Andersen EK, Petersen KB, Andersen AB. A pox-like disease in Cynomolgus monkeys. Acta Pathologica Microbiologica Scandinavia 1959;46 (2):156-76.

[19] Human Monkeypox - Kasai Oriental, Zaire, 1996-1997 MMWR Weekly 1997;4614:306-307.

[20] WHO Monkeypox (December 2019). https://www.who.int/news-room/factsheets/detail/monkeypox [December 9, 2019].

[21] Bartlett J. Monkeypox Review, July15,2003-Medscape-Jul24 2003.

[22] Fauci A. Robert H. Ebert Memorial Lecture-Emerging and Re-emerging Infectious Diseases: The Perpetual Challenge. Milbank Memorial Fund; 2015. https://www.milbank.org/wp-content/uploads/2016/04/0601Fauci.pdf [December 19, 2019].

[23] WHO, Global Change. https://www.who.int/globalchange/climate/summary/ en/index5.html [December 3, 2019]. 
[24] Lloyd-Smith JO. Vacated niches, competitive release and the community ecology of pathogen eradication. Phil Trans Roy Soc B 2013;368:20120150.

[25] Weinstein RA, Nalca A, Rimoin AW, Bavari S, Whitehouse CA. Reemergence of Monkeypox: Prevalence, Diagnostics, and Countermeasures. Clin Infect Dis 2005;41(12):1765-71.

[26] European Centre for Disease Prevention and Control, Monkeypox, Factsheet for Health Professionals. https://www.ecdc.europa.eu/en/all-topics-z/monkeypox/ factsheet-health-professionals [January 22, 2020].

[27] Reynolds Mary G, Lederman Edith R, Karem Kevin, Mombouli Jean-Vivien, Moundeli Omba, Regnery Russell, Harvey Joseph, Wassa-Wassa Demole, Braden Zachary, Damon Inger K, Hughes Christine, Learned-Orozco Lynne A. Prevalence of Antibodies against Orthopoxviruses among Residents of Likouala Region, Republic of Congo: Evidence for Monkeypox Virus Exposure. Am J Trop Med Hyg 2007;77(6):1150-6. https://doi.org/10.4269/ajtmh.2007.77.1150.

[28] Rimoin AW, Mulembakani PM, Johnston SC, et al. Major increase in human monkeypox incidence 30 years after smallpox vaccination campaigns cease in the Democratic Republic of Congo. Proc Natl Acad Sci U S A 2010;107 (37):16262-7.

[29] Heymann David L, Rodier Guénaël. Reemerging pathogens and diseases out of control. Lancet 1997;349:S8-9. , https://linkinghub.elsevier.com/retrieve/pii/ S0140673697900696. https://doi.org/10.1016/S0140-6736(97)90069-6.

[30] Shearer M. Monkeypox in Nigeria? Johns Hopkins Center for Health Security: 2017. https://www.outbreakobservatory.org/outbreakthursday-1/10/12 2017/monkeypox-in-nigeria [October 12, 2017].

[31] Nigeria Centre for Disease Control. Disease Situation Reports. https://ncdc.gov. $\mathrm{ng} /$ diseases/sitreps [December 17, 2019].

[32] Yinka-Ogunleye A, Aruna O, Ogoina D, Aworabhi N, Eteng W, Badaru S, et al Reemergence of Human Monkeypox in Nigeria, 2017. Emerg Infect Dis 2018;24(6):1149-51.

[33] Yinka-Ogunleye A, Aruna O, Dalhat M, Ogoina D, McCollum A, et al. Outbreak of human monkeypox in Nigeria in 2017-18: a clinical and epidemiological report. Lancet Infect Dis 2019;19(8):872-9.

[34] CDC Atlanta, About Monkeypox. https://www.cdc.gov/poxvirus/monkeypox/ about.html.

[35] Rezza G. Emergence of human monkeypox in west Africa. Comment Lancet Infect Dis 2019;19:797-8.

[36] Nigeria Centre for Disease Control. Disease Factsheets. https://ncdc.gov.ng/ diseases/factsheet/54.

[37] Ogoina D, Izibewule JH, Ogunleye A, Ederiane E, Anebonam U, et al. The 2017 human monkeypox outbreak in Nigeria. Report of outbreak experience and response in the Niger Delta University Teaching Hospital, Bayelsa State, Nigeria. PLoS ONE 2019;14(4):e0214229.

[38] NHS England personal communication June 10, 2019.

[39] Vaughan Aisling, Aarons Emma, Astbury John, Balasegaram Sooria, Beadsworth Mike, Beck Charles R, Chand Meera, O'Connor Catherine, Dunning Jake, Ghebrehewet Sam, Harper Nick, Howlett-Shipley Ruth, Ihekweazu Chikwe, Jacobs Michael, Kaindama Lukeki, Katwa Parisha, Khoo Saye, Lamb Lucy, Mawdsley Sharon, Morgan Dilys, Palmer Ruth, Phin Nick, Russell Katherine, Said Bengü, Simpson Andrew, Vivancos Roberto, Wade Michael, Walsh Amanda, Wilburn Jennifer. Two cases of monkeypox imported to the United Kingdom, September 2018. Euro Surveill 2018;23(38). , https:/ www.eurosurveillance:org/content/10.2807/1560-7917.ES.2018.23.38. 1800509. https://doi.org/10.2807/1560-7917.ES.2018.23.38.1800509.

[40] BBC News. https://www.bbc.co.uk/news/uk-england-lancashire-45669247 [September27, 2018].

[41] Public Health England. Monkeypox diagnosed in England - first case of onward transmission. https://assets.publishing.service.gov.uk/government/ uploads/system/uploads/attachment_data/file/739780/Monkeypox_ information_for_primary_care.pdf [December 2019].

[42] Public Health England. https://www.england.nhs.uk/south/wp-content/ uploads/sites/6/2018/10/20180926-monkeypox-2018-external-briefing-notefinal-v3.pdf.pdf [September 26, 2018].

[43] Public Health England. https://www.gov.uk/government/news/monkeypoxcase-confirmed-in-england [December 4, 2019].
[44] Israel Ministry of Health. https://www.health.gov.il/English/News_and Events/Spokespersons_Messages/Pages/12102018_1.aspx [December 12, 2018].

[45] Erez N, Achdout H, Milrot E, Schwartz Y, Wiener-Well Y, Paran N, et al. Diagnosis of Imported Monkeypox, Israel, 2018. Emerg Infect Dis 2019;25 (5):980-3.

[46] Singapore Ministry of Health. https://www.moh.gov.sg/news-highlights/ details/confirmed-imported-case-of-monkeypox-in-singapore [May 9, 2019].

[47] Ng OT, Lee V, Marimuthu K, et al. A case of imported Monkeypox in Singapore. Lancet Infect Dis 2019;19(11):1166.

[48] Li D, Wilkins K, McCollum AM, Osadebe L, et al. Evaluation of the GeneXpert for Human Monkeypox Diagnosis. Am J Trop Med Hyg 2017;96(2):405-10.

[49] Ousman F, Pratt CB, Faye M, Fall G, Chitty JA, et al. Genomic characterisation of human monkeypoxvirus in Nigeria. Lancet Infect Dis 2018;18(3):246.

[50] Falendysz EA, Lopera JG, Lorenzsonn F, Salzer JS, Hutson CL, et al. (2015) Further Assessment of Monkeypox Virus Infection in Gambian Pouched Rats (Cricetomys gambianus) Using In Vivo Bioluminescent Imaging. PLoS NeglTrop Dis 2015;9(10):e0004130.

[51] Oxford Nanopore Technologies website. https://nanoporetech.com/ [December17, 2019].

[52] Carroll M. Retrospective versus real-time Ebola virus. Lancet Infect Dis 2019;19:567-8.

[53] Shchelkunov SN, Totmenin AV, Babkin IV, Safronov PF, et al. Human monkeypox and smallpox viruses : genomic comparison. FEBS Lett 2001;509:66-70.

[54] Fernández de Marco M, del Mar M, Alejo A, Hudson P, Damon IK, Alcami A. The highly virulent variola and monkeypox viruses express secreted inhibitors of type I interferon. FASEB J 2010;24(5):1479-88.

[55] Liszewski MK, Leung MK, Hauhart R, Buller ML, Bertram P, et al. Structure and Regulatory Profile of the Monkeypox Inhibitor of Complement: Comparison to Homologs in Vaccinia and Variola and Evidence for Dimer Formation. J Immunol 2006;76(6):3725-34.

[56] NIH, National Center for Biotechnology Information. https://www.ncbi.nlm. nih.gov/nuccore/?term=monkeypox [December 19, 2019].

[57] Muhlemann B, Jones TC, de Barros Damgaard P, Allentoft ME, et al. Ancient hepatitis B viruses from the Bronze Age to the Medieval period. Nature 2018:557:418-23.

[58] Tiee MS, Harrigan RJ, Thomassen HA, Smith TB. Ghosts of infections past: using archival samples to understand a century of monkeypox virus prevalence among host communities across space and time. $\mathrm{R}$ Soc Open Sci 2019;5:171089.

[59] Falendysz EA, Lopera JG, Doty JB, Nakazawa Y, et al. Characterization of Monkeypox virus infection in African rope squirrels (Funisciurus sp.). PLOS Neg Tropical Dis 2017;11(8):e0005809.

[60] Gao J, Gigante CI, Khmaladze E, Liu P, Tang S, et al. Genome Sequences of Akhmeta Virus, an Early Divergent Old World Orthopoxvirus. Viruses 2018;10:252.

[61] Gigante CM, Gao J, Tang S, McCollum AM, et al. Genome of Alaskapox Virus, A Novel Orthopoxvirus Isolated from Alaska. Viruses 2019;11(8):708.

[62] Beer EM, Rao VB. A systematic review of the epidemiology of human monkeypox outbreaks and implications for outbreak strategy. PLOS Neg Tropical Dis 2019;13(10):e0007791.

[63] Hutson CL, Gallardo-Romero N, Carroll DS, Clemmons C, et al. Transmissibility of the monkeypox virus clades via respiratory transmission: investigation using the prairie dog-monkeypox virus challenge system. PLoS ONE 2013;8:1-12.

[64] Kucharski AJ, Edmunds WJ. Characterising the transmission potential of zoonotic infections from minor outbreaks. PLoS Comput Biol 2015;11(4): e1004154.

[65] Jezek Z, Grab B, Szczeniowski K, Paluku M, Mutombo M. Human monkeypox: secondary attack rates. Bull WHO 1988;66:465-70.

[66] Fine P, Jezek Z, Grab B. The transmission potential of monkeypox virus. Int ] Epidemiol 1988;17:643-50. 